\title{
Migração e trabalho: haitianos em Pato Branco-PR
}

\author{
Cristiane Tonezer \\ Programa de Pós-Graduação em Políticas Sociais e Dinâmicas Regionais / Universidade Comunitária da \\ Região de Chapecó (UNOCHAPECÓ) \\ Ademir Boeno \\ Secretaria da Educação e do Esporte do Paraná (SEED/PR) \\ Myriam Aldana \\ Programa de Pós-Graduação em Políticas Sociais e Dinâmicas Regionais / Universidade Comunitária da \\ Região de Chapecó (UNOCHAPECÓ)
}

Recebido: 02/08/2019 Versão revisada (entregue): 23/09/2019 Aprovado: 01/10/2019

\begin{abstract}
Resumo
Estudos mostram que a migração de haitianos para o Brasil intensificou-se a partir de 2010. São diversas as causas que a explicam, destacando-se as catástrofes ambientais e a precária situação econômica e social do país. No caso específico do município de Pato Branco, no estado do Paraná, os primeiros haitianos chegaram em 2012, recrutados por empresas da construção civil, da agroindústria e da indústria metalúrgica. O presente estudo se debruça sobre o processo de inserção desses trabalhadores no mercado de trabalho do município, as condições laborais enfrentadas por eles e a possibilidade de ascensão social nesse contexto. Para isso, realizou-se uma pesquisa de campo, exploratória, com abordagem qualitativa. Foram entrevistados dez trabalhadores haitianos da cidade de Pato Branco e fez-se análise de conteúdo. Os resultados evidenciaram descontentamento dos entrevistados com o salário recebido e a precarização do trabalho. Mesmo frente a este cenário, eles demonstram esperança em obter maior qualificação profissional e melhores empregos, além de expressarem o desejo de trazer pessoas de seus núcleos familiares do Haiti para Pato Branco.
\end{abstract}

Palavras-chave | Haitianos; migrantes; Pato Branco; trabalho.

Código JEL | J61 J71 O15

\section{Migration and work: haitians in Pato Branco-PR}

\section{Abstract}

Studies show that the Haitians migration to Brazil began in a more intense way onwards 2010, due to several issues, among them stand out catastrophes and the precarious social and economic situation of the country. Within the specific case of Pato Branco (PR), the first Haitians arrived in 2012, recruited by building, agroindustry and metallurgic companies. Since 
this period, it is possible to state the fact that there has been an intense flow of entry and exit of these workers in the city. Therefore, the present study aimed to understand the elements that trigger this process. With this purpose, an exploratory field research with a qualitative approach was developed. For this, ten Haitian workers living in the city of Pato Branco were interviewed and the result of the analysis showed content. The results revealed that the dissatisfaction with the salary earned and the work precarity are the main elements that have been contributing to the migration of these workers from Pato Branco to other cities; even facing these problematic situations, the people interviewed still demonstrate hope in reaching greater professional qualification, better jobs, and also the desire of bringing people of the nucleus family from Haiti to Pato Branco.

Keywords | Haitians; migrant; Pato Branco; work.

JEL-Code | J61 J71 O15

\section{Migración y trabajo: haitianos en Pato Branco-PR}

\section{Resumen}

Estudios muestran que la migración de haitianos para Brasil se intensificó a partir de 2010. Son diversas las causas que la explican, destacándose las catástrofes ambientales y la precaria situación económica y social del país. En el caso específico del municipio de Pato Branco, en el estado de Paraná, los primeros haitianos llegaron en 2012, reclutados por empresas constructoras, agroindustriales y metalúrgicas. El presente estudio buscó comprender el proceso de inserción de estos trabajadores en el mercado laboral municipal, las condiciones laborales enfrentadas por ellos y la posibilidad de ascensión social en este contexto. Para esto, se desarrolló una investigación de campo exploratoria con un enfoque cualitativo. Fueron entrevistados diez trabajadores haitianos de la ciudad de Pato Branco y se hizo un análisis de contenido. Los resultados mostraron la insatisfacción de este público con el salario recibido y la precariedad del trabajo. Incluso en este escenario, los entrevistados muestran la esperanza de lograr una calificación profesional más alta y mejores empleos, además de expresar el deseo de traer a las personas de su núcleo familiar de Haití para Pato Blanco.

Palabras clave | Haitianos; migrantes; Pato Branco; trabajo.

Codigo JEL | J61 J71 O15

\section{Introdução}

Os primeiros haitianos chegaram ao município do Pato Branco, no estado de Paraná, no ano de 2012. Desde então, tem-se observado a existência de um grande fluxo, com entrada e saída de centenas deles nesse município. Este fluxo migratório forma parte do contingente de haitianos que emigraram para o Brasil a partir de 2010, cuja presença se faz notória em diversos estados da federação e 
suas cidades, principalmente naquelas em que há carência de mão de obra no setor agroindustrial. Os estudos de Milesi (2016) sobre imigração haitiana no Brasil revelam que durante os anos de 2012 e 2016, ao todo, 73.077 haitianos se registraram na Polícia Federal, sendo que 51,31\% deles imigraram para os três estados da Região Sul do Brasil (Paraná, Santa Catarina e Rio Grande do Sul). Do total, $55,08 \%$ foram registrados com visto humanitário emitido por consulados ou embaixadas, 40,51\% com base na decisão conjunta do Conselho Nacional de Imigração (CNIg) e Comitê Nacional para os Refugiados (CONARE) e os demais em "outras situações" (MILESI, 2016, p. 2).

Historicamente, o Haiti é marcado por catástrofes naturais que assolam o povo. Em 2008, furacões e tempestades atingiram o país causando mortes. Dois anos depois (janeiro de 2010), um forte terremoto assolou o país causando destruição, mortes, deixando cerca de três milhões de desabrigados. Além desses fenômenos naturais, a história do país é marcada pela instabilidade política, econômica, violência, pobreza e escassez de alimentos. Esses fatores têm contribuído para a imigração haitiana há muito tempo, o que leva ao entendimento de que a mobilidade é uma prática recorrente na história desse povo.

Em estudo sobre os haitianos no sudoeste do Paraná, Giacomini e Bernartt (2015, p. 2) salientam que a cidade de Pato Branco tem sido destino de um número considerável desta população no início da atual década. Estima-se que, em 2016, havia aproximadamente 300 trabalhadores haitianos nas empresas de Pato Branco, além de outros tantos que atuavam na informalidade ou estavam desempregados.

Também é importante sinalizar que, a partir de 2010, o contexto econômico brasileiro contribuiu para a construção da imagem positiva do país, como um local propício para acolhida de mão de obra internacional, sendo uma alternativa de destino para milhares de haitianos.

Quando se reflete sobre a mobilidade humana, pode-se afirmar que o fator laboral é fundamental para a compreensão deste fenômeno mundial. No entanto, existem também outros motivos, tais como encontros familiares, refúgio, asilo, dentre outros que neste artigo não serão abordados na medida em que se privilegiará a análise do trabalho. Isso em função por se considerar que não é possível explicar a presença de fluxos migratórios sem recorrer ao mercado de trabalho e, igualmente, compreendê-lo como fenômeno resultante do modelo de produção capitalista.

Aragonés (2011, p. 86-87) destaca a importância de se entender o segmento dos mercados de trabalho para a compreensão do papel do capital humano, uma vez que "[...] la mobilidad internacional del trabajo se encuentra articulada a la segmentación internacional del trabajo". Na visão do autor, há uma dualidade presente no mercado de trabalho pondo, de um lado, os postos do setor primário, onde estão os cargos profissionais e a gerência, e de outro, o setor secundário com precárias condições e a gerência, e de outro, o setor secundário com precárias 
condições de trabalho e pouca possibilidade de mobilidade laboral e com baixa remuneração. Ao discorrer sobre o setor secundário, o autor observa que,

[...] la disciplina laboral es rígida y se caracteriza por una considerable inestabilidad en el empleo y una elevada rotación de la población trabajadora. En el segmento inferior la educación formal es hasta cierto punto poco importante y puede cubrirse con trabajadores que proceden de sectores desprotegidos como minorías étnicas, jóvenes, mujeres y migrantes (ARAGONÉS, 2011, p. 87).

Nessa perspectiva, o segundo setor tende a fomentar políticas migratórias voltadas para o trabalho temporário, contribuindo para a divisão desta classe, suprimindo direitos econômicos e sociais básicos para uma vida digna. Por serem compreendidos como solução temporária para a carência de mão de obra em determinados setores da economia, os trabalhadores inseridos nestes setores acabam tendo sua dignidade afetada.

O lugar social que os imigrantes ocupam no país e nos locais onde se estabelecem está atrelado à inserção no mercado de trabalho. Por isto, este estudo objetivou analisar as condições de trabalho da população haitiana residente no município de Pato Branco. Os resultados poderão contribuir para o desenvolvimento de ações na interlocução entre organizações, poder público e sociedade civil no tocante à formulação de propostas interventivas e implementação de políticas públicas com um horizonte de justiça social que lhes permita o exercício de cidadania.

\section{Migração e mundo do trabalho}

Ao se tratar da mobilidade humana é muito comum a utilização dos termos migração, imigração e emigração. Apesar da semelhança e proximidade, estas expressões e/ou conceitos possuem significados e diferenças que precisam ser compreendidas para um melhor entendimento dos motivos/causas da mobilidade humana, seja em nível local, regional, nacional ou internacional e as imbricações disso na vida dos sujeitos que a vivenciam.

Migração é entendida como deslocamento e/ou movimento de pessoas dentro de um território onde estavam estabelecidos, para outro local. Os motivos/causas das migrações evidenciam se a mobilidade é algo espontâneo ou determinado por fatores de ordem econômica, social e cultural. As razões ou motivações podem ser individuais (entendido como caso isolado) ou coletivas (características dos fluxos migratórios). Raymundo (2015, p. 20) identifica duas espécies de movimentos migratórios presentes na sociedade contemporânea: “[...] as migrações internas, 
que ocorrem dentro do próprio país (estado-nação) e as migrações internacionais, que pressupõem o cruzamento de fronteiras nacionais e a entrada em outro país".

Além do termo migração, outros dois conceitos auxiliam na compreensão do fenômeno da mobilidade humana: imigrante e emigrante. O primeiro está relacionado à entrada de migrante num país, enquanto o segundo diz respeito à saída de alguém de um país (RAYMUNDO, 2015, p. 21). Nessa perspectiva, a migração pode ser interna (saída do local de origem ou habitual), quando a pessoa se desloca dentro do próprio país nacional, ou externa, saída para outro país, podendo ser ela temporária ou permanente.

Os motivos que levam os indivíduos a migrarem podem ser complexos e multifacetados. De acordo como o Alto Comissariado das Nações Unidas para Refugiados,

[...] migrantes podem deslocar-se para melhorarem suas condições de vida por meio de melhores empregos ou, em alguns casos, por educação, reuniões familiares, ou outras razões. Eles também podem migrar para aliviar dificuldades significativas ocasionadas por desastres naturais, pela fome ou pela extrema pobreza (ACNUR, 2016, s.p.).

Nessa perspectiva, embora sejam inúmeras as causas que levam as pessoas a migrarem, os fatores econômicos e sociais são entendidos como os principais motivadores desse processo, manifestados, sobretudo no desejo de melhores suas condições de vida (educação, saúde, trabalho etc.), o que não é possível no local habitual.

Nas últimas décadas, o fenômeno migratório internacional tem se intensificado, estimulado pela globalização do capitalismo e a criação de um mercado internacional de trabalho. Diante disso, o fluxo migratório tende a se direcionar para locais com maior possibilidade de trabalho, renda e vida melhores, como Europa e Estados Unidos. Empresas, institutos de pesquisa e universidade europeias tem recrutado talentos com predisposição para desempenhar trabalhos em condições inaceitáveis pela população local. Daí o motivo da entrada maciça de profissionais especializados da Índia, China e ex-repúblicas soviéticas. Essa lógica também se repete no concernente às ocupações laborais menos sofisticadas, como hotelaria, restaurantes, construção, agricultura, serviços domésticos, dentre outros. "Muitos nativos rejeitam as vagas existentes que, por sua vez, são preenchidas pelos que vêm da Argélia, Iraque, Irã, Afeganistão, Turquia, Marrocos, ex-Iugoslávia, Albânia, Polônia, República Checa e Ásia" (PASTORE, 2006, p. 298).

Tedesco (2010), estima que, em 2010, cerca de 70\% da mão de obra empregada na construção civil, comércio, limpeza, restaurante e funções domésticas nos países europeus era composta por trabalhadores imigrantes contratados em condições de 
precariedade: "[...] em média, recebiam 60\% a menos de salário que um trabalhador autóctone na atividade, registro na carteira de 'meio expediente' e/ou temporário, ritmos de trabalho de quase o dobro dos trabalhadores nacionais" (TEDESCO, 2010, p. 87). Essa precarização do trabalho, segundo Antunes e Praun (2015), deve-se, sobretudo, à expansão do desemprego estrutural que tem ganhado dimensão global na era moderna. Pode-se dizer, segundo eles, que "[...] há um processo contraditório que, de um lado, reduz o operário industrial e fabril e de outro aumenta o subproletariado, o trabalho precário e o assalariamento no setor de serviços" (ANTUNES; PRAUN, 2015, p. 41-42).

Corroborando com essa discussão, Antunes e Praun (2015, p. 407-408) salientam que na década de 1970 a crise acumulativa do sistema fordista e taylorista afetou o sistema capitalista em sua estrutura econômica. Em razão disso, um conjunto de medidas, articuladas como as antigas formas de exploração do sistema liberal, nos anos 1980, passou a redimensionar a divisão internacional do trabalho, fortalecido pelo capital financeiro e marcado pelo número cada vez mais reduzido de corporações transnacionais e submissão de trabalhadores (classe que vive do trabalho) a baixos patamares salariais e precárias condições de vida. $O$ autor ressalta, ainda, que essas medidas resultaram na transferência de parte das atividades produtivas de grandes empresas para os países periféricos. Isso resultou na redução do proletariado nos países de capitalismo avançado e impulsionou a expansão de contingentes significativos de trabalhadores em diversos países do Sul, em setores de serviços, agroindústrias e, sobretudo, na indústria.

Antunes e Praun (2015, p. 409, grifos no original) lembram que, no Brasil, a partir da década de 1990,

[...] as transformações geradas pela nova divisão internacional do trabalho foram de grande intensidade, já que partiram de uma dinâmica interna, característica dos países de industrialização dependente, fundada na superexploração da força de trabalho. A imposição de baixos salários, associados a ritmos de produção intensificados e jornadas de trabalho prolongadas, foi ainda acentuada pela desorganização do movimento operário e sindical, impostas pela ditadura militar.

Nesse contexto, o liberalismo surgiu com uma nova roupagem (neoliberalismo), caracterizado, sobretudo, pela precarização do trabalho, salários ruins e baixa qualidade de vida da grande massa de trabalhadores, impactando, inclusive, na saúde desses.

A nova divisão internacional do trabalho estabeleceu, concomitantemente, um novo mapa de acidentes e doenças profissionais. Essas alterações acabam sendo perceptíveis com mais 
clareza no interior das corporações de grande porte, nas quais a gestão dos processos de trabalho é potencializada pela presença de robôs e sistemas informacionais e comunicacionais sofisticados. (ANTUNES; PRAUN, 2015, p. 411).

Contribuindo com essa análise, Mendonça (2014, p. 22) destaca que nas décadas de 1980 e 1990 os países latino-americanos passaram por um processo de reestruturação pautado na abertura econômica. O resultado foi a deterioração dos setores primários e secundários, acabando por diminuir a demanda por mão de obra e, consequentemente, aumentando as taxas de desemprego. Esse processo esteve intimamente ligado à flexibilização da legislação trabalhista e contribuiu para precarização de empregos, diminuindo a capacidade atrativa de imigrantes para a América Latina. Por outro lado, a crise econômica vivida pelos países desenvolvidos e a crescente flexibilização do trabalho contribuíram para o fluxo migratório dentro da própria região. Em razão disso, um conjunto de medidas, articuladas com as antigas formas de exploração do sistema liberal, nos anos 1980, passou a redimensionar a divisão internacional do trabalho, fortalecido pela capital financeiro e marcado pelo número, cada vez mais reduzido, de corporações transnacionais e submissão de trabalhadores a baixos patamares salariais e precárias condições de vida.

A flexibilização das leis trabalhistas na década de 1990 desencadeou o fenômeno da terceirização e, por consequência, a precarização das relações de trabalho e a transferência da responsabilidade sobre os custos ao trabalhador. Nesse cenário está o imigrante, que se desloca em busca de melhores condições de vida e subsistência. De acordo com Antunes e Praun (2015, p. 413), “[...] nas épocas de crise estrutural, acentua-se à precarização estrutural do trabalho em escala global, da qual o trabalho imigrante é a sua expressão mais vivível e brutal".

Contribuindo com essa discussão, Pastore (2006) destaca que a sociedade contemporânea assiste à intensificação do processo de terceirização, personificando a globalização da oferta de trabalho. A tendência é que os países ricos transfiram atividades laborais aos países que conseguem, mesmo subdesenvolvidos, qualificar mão de obra para as novas atividades de produção e venda. Nessa perspectiva, os países que possuem boa educação, profissionais bem treinados, flexibilização das leis trabalhistas e baixa remuneração salarial tendem a ter mais "vantagens". Esse cenário é ideal para as grandes empresas reduzirem custos e aumentarem lucros.

No caso específico do Brasil, a retomada do crescimento econômico no final dos anos 1990 e, principalmente, no início dos 2000, contribuiu para o aumento da taxa de entrada de imigrantes no país. Segundo Mendonça (2014, p. 28), “[...] entre 2005 e 2010 o número de imigrantes, incluindo os brasileiros natos que regressavam ao país, chegou a 268 mil.". Corroborando com esta constatação, Dal Magro e Risson $(2015$, p. 1) destacam o contexto econômico brasileiro da época 
como importante destino migratório da força de trabalho internacional, com destaque para a imigração haitiana, sobretudo, para o oeste de Santa Catarina e sudoeste do Paraná, onde, na maioria das vezes, passaram a ocupar postos de trabalho precários e rotativos, com baixa remuneração e com riscos de adoecimento. Além disso, a grande carência de políticas públicas direcionadas a esta população os deixam vulneráveis à exploração do trabalho.

Para Miraglia (2008, p. 85), “[...] o ser humano se realiza e se afirma quando lhe é assegurada a dignidade social, correspondente ao mínimo existencial atribuído a toda pessoa humana.". Nesse sentido, o trabalho é visto como um mecanismo que possibilita às pessoas a inserção na sociedade capitalista e nela se firmarem. É por meio da remuneração proveniente do trabalho que o ser humano acessa as condições de uma vida digna, como descreve a Declaração Universal dos Direitos Humanos (ONU, 1948, [s.p.]), em seu artigo 23:

[...] todo ser humano que trabalhe tem direito a uma remuneração justa e satisfatória, que lhe assegure, assim como a sua família, uma existência compatível com a dignidade humana, e a que se acrescentarão, se necessário, outros meios de proteção social.

Seguindo essa linha, Engels (1986, p. 4) argumenta que "[...] o trabalho é a condição básica e fundamental de toda a vida humana". Para os economistas, ele é fonte de toda a riqueza, mas para o trabalhador é muito mais que isso, é a possibilidade de vida digna.

A Constituição Federal do Brasil (BRASIL, 1988), em seu Art. $3^{\circ}$, enumera como objetivos fundamentais do país a construção de uma sociedade justa e solidária, a irradicação da pobreza e da marginalização, assim como promover o bem de todos, independentemente da origem, cor, raça, sexo ou idade, entre outras formas de discriminação. Essas prerrogativas são reforçadas no Art. $4^{\circ}$, que enfatiza os direitos humanos como princípio e fundamento de todo tipo de convenção internacional. Desse modo, a dignidade da pessoa humana vai de encontro aos direitos fundamentais do ser humano em seus diversos aspectos. Assim, a dignidade está assegurada no campo teórico. Contudo, a concretude da vida cotidiana se apresenta como um desafio para milhares de pessoas que precisam sobreviver.

O desenvolvimento das tecnologias de produção e informação possibilitou a globalização da produção e circulação de mercadorias, mas não se mensurou os impactos na vida do trabalhador e suas condições de trabalho. O trabalho precário, mesmo nos países desenvolvidos ou em desenvolvimento, apresenta-se, muitas vezes, como a única opção para pessoas com baixa escolarização. Isso acaba reforçando o estereótipo social de que pessoas com pouca instrução só podem fazer trabalhos de baixa remuneração e sem garantias. 
Para Pastore (2006), a globalização acaba produzindo dois tipos de imigrante: o desejado e o indesejado. O desejado é aquele que possui mão de obra qualificada. $\mathrm{O}$ indesejado, por sua vez, é aquele com baixa qualificação. Os imigrantes com baixa qualificação tendem a ter mais dificuldade para entrar de forma legal nos países receptores, optando pela entrada e permanência ilegais, o que os colocam em condições de trabalhos forçados e mal remunerados, além de serem alvo de preconceitos e discriminações diversas. O imigrante indesejado passou a ser visto como ameaça à cidadania e à ordem pública das nações receptoras. Com base nessa argumentação, os países têm despendido esforços políticos e jurídicos para controlar, selecionar e punir aqueles que não se enquadram aos processos normativos para adaptar o fluxo migratório às necessidades do mercado de trabalho (PASTORE, 2006, p. 45).

Por entender que o imigrante é uma força de trabalho transitória, ele acaba sendo destituído de sua dignidade e humanidade em seu mais amplo sentido. Mesmo sendo parâmetro regulatório entre o Estado e seus cidadãos, a Declaração Universal dos Direitos Humanos não conseguiu dar conta da relação entre o Estado e o estrangeiro. No intuito de construir uma legislação mais específica sobre essa questão, a Organização Internacional do Trabalho (OIT, 2005) promoveu duas convenções. Dentre as diversas tratativas, essas convenções prescreveram critérios para o recrutamento de estrangeiros e tratamento igualitários para a população local e imigrantes no que se refere ao mundo do trabalho, independente da raça, cor, sexo ou religião, além do combate aos empregos ilegais e ao tráfico de pessoas.

Conforme Brito et al. (2009, p. 35), a orientação da OIT é a de que "as condições laborais devem ser orientadas para o trabalho decente". Mas o que é trabalho decente? Conforme a instituição, em seu Manual de capacitação e informação sobre gênero, raça, pobreza e emprego: guia para o leitor (OIT, 2005, p. 3), "trabalho decente" é "[...] uma ocupação produtiva adequadamente remunerada, exercida em condições de liberdade, equidade, segurança e que seja capaz de garantir uma vida digna". $\mathrm{Na}$ concepção da referida organização, a superação da pobreza e da exclusão dependem do trabalho decente. Porém, no Brasil, segundo Vendruscolo (2016, p. 8), muitos trabalhadores haitianos se deslocam para regiões distintas do país em busca de oportunidade, submetendo-se, muitas vezes, à precarização e à exploração.

\section{Procedimentos metodológicos}

Com interesse de aprofundar o entendimento sobre a relação entre processo migratório e trabalho, o presente estudo visa entender as condições laborais dos imigrantes haitianos na cidade de Pato Branco. Localizado no sudoeste do Paraná, a 30 quilômetros da divisa com o estado de Santa Catarina e distante 433,35 
quilômetros da capital Curitiba, Pato Branco é um município de forte empreendedorismo e inovação tecnológica. A população é estimada em 80.710 habitantes (IBGE, 2017) e tem atividade econômica diversificada, com destaque para a indústria produtora de alimentos (frigorífico), construção civil e metalurgia, setores estes que concentram o maior número de trabalhadores.

O bom momento econômico vivido pelo município no início dos anos 2010 gerou uma grande demanda de mão de obra em setores produtivos de empresas pato-branquenses, sobretudo, na linha de produção. No entanto, essas encontram dificuldade para preencher as vagas de trabalho com a população local, que não se sujeitava ao tipo de trabalho ofertado e ao salário praticado por elas. Diante disso, o empresariado vislumbrou nos imigrantes haitianos a solução para a carência de mão de obra. Desde então, mais precisamente a partir de 2012, um número considerável de haitianos chegou à cidade motivado pela propaganda de emprego e a esperança de construção de vida próspera para si e para familiares.

Para aproximar-se dessa população foi necessário fazer um trabalho exploratório a fim de saber onde eles se encontravam e quais instituições costumam fazer o acolhimento deles. Nesse intuito, foi realizada visita a sindicatos (construção civil, produção de alimentos e metalurgia), instituição religiosa (Igreja Católica) e Secretaria de Assistência Social do município de Pato Branco. Uma vez identificado onde se situavam, foi estabelecido contato com eles no intuito de realizar entrevistas semiestruturadas que permitissem conhecer suas condições laborais. Assim sendo, estabeleceram-se alguns critérios para a seleção dos participantes, a saber: estar residindo e trabalhando no município há pelos menos seis meses e ter idade superior a 18 anos. A seleção dos sujeitos da pesquisa foi feita de forma aleatória, conforme a disponibilidade e livre aceitação, como exige uma pesquisa qualitativa.

Ao todo, foram entrevistados nove haitianos e uma haitiana com faixa etária entre 26 e 49 anos. Oito sujeitos da pesquisa trabalhavam em frigoríficos do município (sete como auxiliar de produção e um como faxineiro), um trabalhava em uma empresa de derivados de cimento (auxiliar de serviços gerais) e uma entrevistada trabalhava de diarista.

Destacam-se como categorias analíticas: formação e trabalho; trabalho e salário; e trabalho e família. A construção das duas primeiras deu-se a partir do referencial teórico, isso porque se observou que as condições de trabalho estão diretamente relacionadas à formação (qualificação profissional) dos indivíduos. O referencial teórico também sinalizou que a remuneração (salário) é um fator importante para uma vida digna. Por sua vez, a categoria trabalho e família derivou dos resultados empíricos, pois se notou que o trabalho para os imigrantes haitianos entrevistados não diz respeito apenas a eles, mas aos seus familiares, que, muitas vezes, residem no Haiti e também dependem de parte da remuneração dele proveniente. 


\section{Análise e discussão de dados}

\section{Formação e trabalho}

Uma das formas essenciais para acessar postos de trabalhos com maior remuneração é a formação e/ou qualificação. Isso é vital para que o migrante seja reconhecido na sua profissão. Quem faz curso superior está preocupado com a sua qualificação para o mercado de trabalho, sendo esta também uma preocupação das instituições de ensino. Contudo, tem-se observado que, mesmo com ensino superior, muitas pessoas têm encontrado dificuldade de encontrar trabalho adequado à sua área de formação, com destaque para os imigrantes haitianos entrevistados.

No caso estudado observou-se que muitas empresas se interessam em contratar mão de obra para trabalhos precarizados, que não requerem qualificação e oferecem baixa remuneração, geralmente em linhas de produção, como é o caso das empresas de Pato Branco que empregam haitianos. Mesmo assim, os trabalhadores entrevistados demostraram necessidade de permanecer trabalhando no município, apesar do cenário precarizado e do baixo retorno financeiro, como é o caso de um entrevistado de 49 anos, com ensino médio incompleto, que trabalha na linha de produção de um frigorífico: "[...] enquanto tiver trabalho permaneço por aqui, se a empresa me mandar embora, vou para outra cidade onde tenha trabalho". Outro participante, de 41 anos, com formação superior em Direito, também atrelou a sua permanência à possibilidade de trabalho no município: “[...] enquanto tiver trabalho (frigorífico) pretendo continuar aqui em Pato Branco, mas se ficar desempregado terei de ir para outra cidade." Um terceiro (31 anos, com formação superior incompleta em administração), que trabalhava como aduaneiro no Haiti, também expressou o desejo de continuar trabalhando na mesma empresa (frigorífico) se houver possibilidade de promoção.

Com base nas observações dos entrevistados sobre as condições laborais dos trabalhadores haitianos nas empresas pato-branquenses, constatou-se que um grande número deles possui formação superior. Dos 10 entrevistados, sete são diplomados, um possui curso superior incompleto, um ensino médio completo e outro, o ensino médio incompleto. No entanto, mesmo que a grande maioria deles possua ensino superior, os cargos que ocupam nas empresas (auxiliar de produção, serviços gerais e faxineiro) não correspondem às respectivas formações.

Segundo entrevistados, as empresas não fazem distinção entre os que possuem ou não formação superior, pois o interesse delas é contratar trabalhadores para a linha de produção, onde não se exige escolaridade avançada. Sobre isso, um entrevistado de 32 anos com ensino médio completo e que trabalhava de mecânico em seu país, relata que vários colegas seus com ensino superior (engenheiros, advogados, professores etc.) foram contratados para fazer a mesma função que ele (linha de produção). Essa análise também é feita por outro 
participante de 33 anos, com formação superior em Direito que também trabalha na linha de produção de um frigorífico: "[...] as empresas não contrataram nenhum estrangeiro por ser advogado ou por ter formação superior, elas só querem gente pra colocar na linha de produção, cortar frango, e para se fazer isso não precisa muito estudo".

Outro entrevistado com formação incompleta em Contabilidade, acredita que a sua formação contribuiu para a sua mudança de função no frigorífico que trabalha: "[...] iniciei na linha de produção e agora faço parte da Comissão Interna de Prevenção de Acidentes (CIPA)". Sua tarefa é observar o ambiente de trabalho e detectar situações de possíveis acidentes aos quais os funcionários possam estar expostos (chão molhado, exposição à eletricidade, uso incorreto de equipamentos etc.), anotar tudo e apresentar nas reuniões com os demais membros. Contudo, essa função é rotativa na empresa, a cada ano mudam os membros da comissão. Ao ser questionado se essa nova função melhorou o seu salário, ele respondeu que não, que a empresa não paga mais por isso. Percebe-se, nesse caso, que a única vantagem desse trabalhador em relação aos demais é a de não desempenhar as mesmas tarefas que seus colegas. No entanto, isso não significa uma melhoria salarial. Além disso, esse trabalhador está sujeito à temporalidade e rotatividade da função, podendo retornar futuramente à linha de produção.

Em relação à situação de trabalhadores haitianos no Brasil, estudos de Magalhães (2017) auxiliam-nos na compreensão deste cenário. O autor investiga a situação de haitianos em Santa Catarina e evidencia que a concentração de empregados estrangeiros em setores mais precários do trabalho formal no Brasil, reforça a clássica estratégia de utilização da mão de obra migrante em empregos subremunerados (MAGALHÃES, 2017, p. 199). Corroborando com esse dado, um dos participantes da pesquisa, que trabalhava como professor no Haiti, afirma que $50 \%$ da força de trabalho do frigorífico onde trabalha é composta por haitianos, ocupando funções que não exigem muita escolaridade e têm baixa remuneração.

Outro fator que impede que a formação do imigrante tenha importância para o acesso a uma determinada vaga de trabalho está relacionado ao processo burocrático de validação do diploma estrangeiro junto ao Ministério da Educação (MEC). Conforme dados do Ministério da Educação (MEC), o estrangeiro deve

[...] entrar com um requerimento de revalidação em uma instituição pública de ensino superior do Brasil. De acordo com a regulamentação, apenas as universidades públicas podem revalidar diplomas. Deverão ser apresentados, além do requerimento, cópia do diploma a ser revalidado, instruído com documentos referentes à instituição de origem, duração e currículo do curso, conteúdo programático, bibliografia e histórico escolar. (BRASIL, 2017, s.p.). 
Esse processo de validação de diploma não se aplica apenas a estrangeiros, mas a todos que fizeram curso superior fora do país. Além do pedido de revalidação, o requerente deverá pagar taxas de custeios do processo com preço a ser estipulado pelas instituições de ensino. O julgamento da compatibilidade das áreas de conhecimento e o nível de titulação serão avaliados por uma comissão especial composta por professores da própria universidade, que, em caso de dúvida, poderá solicitar que o requerente faça exames e provas em Língua Portuguesa para chegar à equivalência de cursos. Feitos provas e exames, caso não sejam comprovadas as condições mínimas exigidas para a convalidação, a instituição poderá exigir estudos complementares. Todo esse processo pode levar até seis meses (BRASIL, 2017, s.p.).

Esse trâmite moroso e burocrático tem dificultado a validação dos diplomas de curso superior de imigrantes haitianos no Brasil, impossibilitando-os de pleitear empregos com maior remuneração, impelindo-os para trabalho precarizados com alta rotatividade, instabilidade e baixo retorno financeiro (linha de produção e trabalhos informais). Cavalcanti (2017, p. 167), salienta que "[...] para os que não concluíram seus cursos, o desafio será ingressar numa universidade pública, já que na condição de imigrante terão que seguir as mesmas regras estipuladas para os brasileiros que queiram ingressar no ensino superior".

Frente a isso, restam-lhes três alternativas: enfrentar o trâmite burocrático para validar seus diplomas, fazer um novo curso superior ou desistir. Para muitos haitianos residentes em Pato Branco, trabalhar e estudar no Brasil é um sonho. No entanto, as informações obtidas a partir do campo de estudo demostram que eles têm encontrado dificuldade para acessar curso superior na cidade, seja pela falta de oferta de bolsas de estudo nas instituições públicas e privadas, com raras exceções, seja pela impossibilidade financeira de arcar com as mensalidades dos cursos. Dos 10 sujeitos ouvidos, apenas dois estão cursando ensino superior. Um deles cursa Administração em uma instituição particular, com bolsa de 50\% de desconto, e outro estuda Letras pelo sistema de ensino a distância semipresencial, sem bolsa.

Dois entrevistados manifestaram expectativa de poder estudar e pleitear trabalhos com maior remuneração em Pato Branco. Um deles sonha terminar o curso de Letras e trabalhar na área de docência, o outro deseja terminar o curso de informática e ingressar no curso de contabilidade (fornecido por um colégio estadual), para, futuramente, conseguir um emprego com melhor remuneração. Outro sonha em cursar Administração e trabalhar na área futuramente.

Esse cenário de desvalorização da formação e a dificuldade para acessar o curso superior na referida cidade tem contribuído para a desmotivação desses trabalhadores. A falta de reconhecimento de seus diplomas e de oportunidade para fazer um curso superior os impossibilita de pleitearem empregos com melhor remuneração e os sujeita a trabalhos precarizados e com salários baixos. 


\section{Trabalho e salário}

Em estudos sobre trabalhadores haitianos no Brasil, Fernandes e Castro (2014, p. 64) salientam que "[...] os postos de trabalho ocupados por eles no Brasil são, na maioria dos casos, de baixa remuneração, com salários que variam entre um a um salário mínimo e meio". Contribuindo com essa análise, a presente pesquisa constatou, por meio das entrevistas, que os trabalhadores haitianos da cidade de Pato Branco, de maneira geral, estão insatisfeitos com seu salário, considerado insuficiente para pagarem as despesas pessoais, como aluguel, água, energia elétrica, dentre outros. Para diminuir os gastos e "fazer sobrar alguma coisa no fim do mês", é muito comum dividirem aluguel, como relatou um deles, que chegou a Pato Branco em 2013 e atualmente trabalha de auxiliar de produção:

[...] com o salário de $\mathrm{R} \$ 1.200$ que recebo dá pra pagar aluguel, água, luz e comer. Dá pra se virar com esse salário porque muitos haitianos dividem aluguel com outros haitianos para diminuir os gastos e fazer a vida um pouquinho melhor.

Essa análise é corroborada por outro trabalhador de 29 anos, formado em contabilidade, que afirma que pelo trabalho pesado que faz, em uma empresa de derivados de cimento, e pela carga horária diária oito horas, $\mathrm{R} \$ 1.100$ é pouco, pois precisa pagar suas despesas como aluguel, água, luz, gás, alimentação e a mensalidade da faculdade $(\mathrm{R} \$ 281)$.

Observou-se também que as empresas que absorvem mão de obra haitiana no município de Pato Branco contabilizam e/ou controlam as horas de trabalho de seus funcionários, descontando na folha do mês as ausências no trabalho, mesmo com atestados médico, a perda de direitos ao seguro-desemprego e multa rescisória em caso de pedido de demissão. Um dos entrevistados, que trabalha de auxiliar de serviços gerais, argumentou que "[...] se o funcionário faltar um dia no trabalho ele tem $\mathrm{R} \$ 100$ descontados do vale alimentação e a falta do dia também é descontada em folha no final do mês". Perguntado se essa situação acontece só com os haitianos, ele respondeu que não, que isso se aplica a todos os funcionários indistintamente. Nessa perspectiva, tal prática é algo inerente ao tipo de função que ocupa o trabalhador e não específico à condição de imigrante.

No entanto, um participante da pesquisa, de 41 anos, afirmou que o frigorífico em que trabalha faz distinção entre brasileiros e estrangeiros no que diz respeito a atestados médico: "[...] se um haitiano pegar um atestado médico de cinco dias, eles aceitam três e descontam dois. Sei que no caso dos brasileiros eles aceitam o atestado de forma integral". Outro sujeito de 26 anos afirma que a empresa metalúrgica em que trabalha "[...] tem o hábito de descontar de seus funcionários até mesmo a ausência de algumas horas do trabalho, mesmo que ela seja justificada com atestado médico ou tenha sido comunicada com antecedência". 
Por essa razão, esses trabalhadores procuram não faltar ao trabalho, pois descontos, por mínimos que sejam, acabam dificultando ainda mais a sua sobrevivência, como pontua um dos entrevistados que trabalha na linha de produção de um frigorífico: "o patrão não gosta que falte ao trabalho, não quero perder esse emprego". O entrevistado ainda comenta que, em três anos de empresa, só faltou ao trabalho meio dia e que já trabalhou doente para não ter descontos no final do mês.

No que se refere às leis, a prática de descontos citada anteriormente é legal e se aplica a todos os trabalhadores, imigrantes ou nacionais. Existem critérios estabelecidos para que os dias ou horas de ausência do trabalho sejam abonadas. A preferência, antes de tudo, é que o trabalhador seja avaliado por médicos ou serviços de saúde mantidos pela empresa, o que significa que nenhum atestado médico emitido pela rede pública de saúde ou médico particular tem validade sem o parecer dos profissionais de saúde da empresa, como prescreve a CLT no Art. $6^{\circ}$, letra "f", da Lei 605/1949.

A doença será comprovada mediante atestado médico da instituição de previdência social a que estiver filiado o empregado, e, na falta deste e sucessivamente, de médico do Serviço Social do Comércio ou da indústria; de médico da empresa ou por ela designado; de médico a serviço de repartição federal, estadual ou municipal, incumbida de assuntos de higiene ou de saúde pública; ou não existindo estes, na localidade em que trabalhar, de médico de sua escolha. (BRASIL, 1949, s.p.).

Outra constatação feita, a partir da pesquisa, foi que há descontos mensais em folha referentes a gastos com a locomoção desses trabalhadores até seus locais de trabalho. Oito dos 10 entrevistados afirmam usar o transporte público, um não usa e outro usa o próprio carro. Questionados se o vale-transporte é fornecido pelas empresas, ambos afirmaram que sim, mas que há desconto no final do mês. Ao verificarmos a legalidade dessa situação, encontramos a seguinte determinação, pela Lei n. 7418, de 16 de dezembro de 1985: “[...] o empregador deve participar dos gastos de deslocamento do trabalhador com a ajuda de custo equivalente à parcela que exceder a 6\% (seis por cento) de seu salário básico" (BRASIL, 1985, s.p.). Nessa perspectiva, não há ilegalidade nessa prática, desde que os descontos estejam em consonância com o prescrito pela lei. Com relação ao entrevistado que usa o próprio carro para ir ao trabalho, não lhe é assegurado direito ao ressarcimento por parte da empresa, uma vez que não faz uso de transporte público.

Além das estratégias de controle sobre a assiduidade dos trabalhadores, observouse também uma prática de coibição em eventuais pedidos de demissão, ocasionando a perda de direitos trabalhistas, como multa rescisória e direito ao 
seguro-desemprego. Sem condições financeiras de migrar para outras cidades em busca de melhores empregos e remuneração, o trabalhador se vê "coagido" a continuar no mesmo trabalho para se manter, como destacou um entrevistado que é faxineiro em um frigorífico:

[...] se peço ao patrão para fazer um acordo para ir pra outra cidade tentar uma vida melhor e poder estudar, acham que estou abusando e só me liberam se eu pedir a conta, aí perco os direitos trabalhistas, saio sem nada. Já conversei com outros haitianos que moram em outras cidades e eles me falaram que lá é diferente, tem mais vantagem [oportunidade de estudo e trabalho e negociação com os patrões para liberar FGTS e seguro-desemprego] para haitianos.

Outra constatação feita nesta pesquisa foi a de que os trabalhadores haitianos não veem perspectivas de melhoria salarial ou possibilidade de mobilidade de setor nas empresas em que trabalham, como relatou um deles, que há três anos reside no município: “[...] se uma pessoa está há seis anos na empresa, ela ganha a mesma coisa que uma pessoa que está lá há dois meses. Se ela entra na empresa pra fazer determinada função, ela só vai fazer aquilo". Com relação à carga horária de trabalho, outro participante, formado em Direito, asseverou que:

[...] diferentemente do que acontece no Haiti, no Brasil o funcionário é praticamente exclusivo da empresa, pois trabalha oito horas diárias [de segunda a sexta] e faz horas extras nos finais de semana e feriados quando a empresa solicita.

A prática de controle laboral, como descontos em folha de pagamento em eventuais ausências e a angústia de a remuneração não ser suficiente para arcar com as despesas pessoais, assim como a exposição a trabalhos insalubre, afetam a saúde dos trabalhadores, como afirmam dois entrevistados:

[...] trabalho no pior setor da empresa, tem muito pó, meu rosto tem um monte de bolinhas devido à alergia.

[...] meu ambiente de trabalho é muito frio [câmara fria em um frigorífico] e, por conta disso, vivo com problemas de garganta, pois saio do ambiente de trabalho que é bem frio e entro no ônibus [transporte público] que é bem quente, o que resulta em choque térmico. 
Grande parte desses trabalhadores se sujeita às condições de trabalho e controle laboral impostos pelas empresas por necessidade e/ou por não terem alternativas, pois precisam se manter, como relatam dois deles: "aceito continuar trabalhando apesar das dificuldades, pois não posso dormir na rua"; "[...] tenho que aceitar isso, não estou no meu país; não é aquilo que gostaria de fazer, mas a necessidade me fez acostumar". Diante dessa realidade, os trabalhadores que têm condições financeiras acabam indo embora do município e os que não dispõem de recursos para isso acabam permanecendo, sujeitando-se, na maioria dos casos, a trabalhos precarizados e de baixo salário. Essa situação se torna ainda mais agravada para aqueles que deixaram dependentes no Haiti e que precisam os assistir financeiramente.

\section{Trabalho e família}

O processo migratório segmenta a família, no caso específico dos haitianos, os depoimentos colhidos junto aos participantes desta pesquisa revelam que muitos deles saíram do Haiti em busca de melhores condições de vida e subsistência, deixando para trás filhos, esposas, pais, irmãos (pessoas que fazem parte do núcleo familiar). A possibilidade de trabalho, renda e melhores condições sociais para si e seus familiares tem atraído um número considerável deles para o município de Pato Branco desde 2012. No entanto, a ascensão social sonhada por eles é quase utópica, pois têm encontrado dificuldade para acessar postos de trabalho com boa remuneração e condizentes com a formação superior que muitos possuem. Assim como barreiras econômicas e burocráticas para validar seus diplomas ou cursar uma faculdade no Brasil, restando-lhes trabalhos precarizados, rotativos e com baixo retorno financeiro, o que acaba lhes frustrando as expectativas que os motivaram a migrar para a cidade de Pato Branco. Conforme os relatos dos entrevistados, a obrigação de ajudarem familiares e a necessidade de se manterem nessa cidade os fazem "reféns" das condições laborais e remuneratórias das empresas onde estão inseridos.

Dos 10 sujeitos desta pesquisa, cinco afirmam ter necessidade de enviar dinheiro para ajudar familiares no Haiti, mas encontram dificuldade de fazê-lo por conta do baixo salário que recebem e dos gastos pessoais para se manterem no município. Como afirma um entrevistado de 49 anos que trabalha como auxiliar de produção em um frigorífico: "[...] deixei seis filhos em meu país e preciso enviar-lhes dinheiro, mas com o salário de $\mathrm{R} \$ 1.100$ que ganho fica difícil fazer depósitos mensais, por isso faço isso a cada três ou quatro meses". Outro participante, com formação superior em Direito, também pontua que o salário que ganha é insuficiente para arcar com as despesas pessoais e ajudar familiares - "preciso juntar mais de $\mathrm{R} \$ 350$ para mandar 100 dólares para minha família no Haiti”.

Mesmo com o cenário desfavorável aos trabalhadores haitianos, observou-se que muitos deles apresentam o desejo de trazerem familiares para o Brasil, mais 
especificamente para Pato Branco, sobretudo, mulheres haitianas, o que tem se confirmado com a chegada de um número considerável delas nos últimos dois anos (esposas, irmãs, primas etc.). No entanto, esse público feminino tem encontrado dificuldade para conseguir trabalho no município, como informou um dos entrevistados: "[...] trouxe minha esposa do Haiti em agosto de 2016, mas ela ainda não conseguiu trabalho nessa cidade". Outro informou que a empresa onde trabalha (frigorífico) "há mais de dois anos não contrata haitianas". Questionado sobre o motivo, ele afirmou que "isso é uma política interna da empresa".

Frente a essa realidade, muitos haitianos têm migrado de Pato Branco para outras cidades com a perspectiva de melhores condições de vida, trabalho e renda. Por outro lado, uma parcela considerável de trabalhadores tende a continuar nas empresas pato-branqueses por prudência ou medo do desemprego, já isso afetaria de forma direta seus familiares que ficaram no Haiti e dependem economicamente deles.

\section{Considerações finais}

A precarização do trabalho manifestada na exploração da mão de obra, baixa remuneração e constatação de que suas formações (obtidas em seu país de origem) não lhes qualifica para empregos condizentes são fatores que têm contribuído para a frustração de muitos trabalhadores haitianos em Pato Branco. Um participante desta pesquisa, que está no município desde 2015, relatou que muitos haitianos venderam tudo o que tinham no Haiti (carro, casa, bens etc.) para vir para ao Brasil, em específico, para a cidade de Pato Branco, com a expectativa de ganhar dinheiro, mas ao chegarem se frustraram com o baixo salário e com o cenário de precarização do trabalho.

A observação do campo do estudo e os depoimentos dos participantes desta pesquisa evidenciam que muitos haitianos que residem na cidade de Pato Branco possuem curso superior, mas têm encontrado dificuldade para validar seus diplomas no Brasil por conta dos trâmites burocráticos, custo e morosidade do processo o que os impede de acessar trabalhos com melhor retorno financeiro. Por conta disso, os postos de trabalho ocupados por eles no município de Pato Branco, em sua grade maioria, são em setores que não exigem escolaridade avançada, geralmente em linhas de produção em frigoríficos e metalúrgicas.

Ficou evidenciado também que muitos desses trabalhadores estão expostos a ambientes de trabalho que lhes oferecem risco à saúde (poeira, calor e frio). Contudo, essas condições laborais não são particulares aos imigrantes, mas ao tipo de trabalho realizado. Em outros termos, independentemente de ser imigrante ou não, o trabalhador está sujeito a trabalhos degradantes, repetitivos, monótonos, rotativos e exploratórios que podem gerar desumanização, pois o ritmo de 
produção está atrelado às máquinas. Observou-se, também, que as empresas exercem controle sobre a assiduidade desses trabalhadores por meio de desconto em folha sobre eventuais ausências - mesmo justificadas com atestados médico.

Diante desse cenário, muitos desses trabalhadores já foram embora da cidade de Pato Branco por não verem perspectivas de melhora salarial e mobilidade de setor nas empresas desse município. Por outro lado, uma parcela considerável deles continua nessa cidade por necessidade e medo do desemprego, pois precisa se manter e auxiliar financeiramente pessoas do núcleo familiar que ficaram no Haiti. Frente a esta realidade, esses trabalhadores acabam se sujeitando às condições de trabalho e aos salários oferecidos. Aliado a isso, muitos deles nutrem o desejo de reunião familiar, o que tem contribuído para a vinda de outros haitianos para a referida cidade, principalmente mulheres haitianas, sobretudo, a partir de 2016.

Conclui-se, por fim, que a inserção de mão de obra haitiana no mercado de trabalho de Pato Branco não foge do que a teoria nos traz em termos internacionais, uma vez que esses trabalhadores tendem a ocupar postos de trabalho precarizados, com alta rotatividade e baixa remuneração o que retrata a realidade vulnerável de milhares de migrantes no mundo inteiro.

Este trabalho atingiu seu objetivo de analisar as condições de trabalho da população haitiana no município de Pato Branco. Condições estas que seguem a lógica de exclusão presente nas sociedades capitalistas, materializada por meio da precarização do trabalho.

\section{Referências}

"ALTO COMISSARIADO DAS NAÇÕES UNIDAS PARA REFUGIADOS ACNUR. "Refugiados" e "Migrantes": perguntas frequentes. Brasília, 2016. Disponível em: <http://www.acnur.org/portugues/2016/03/22/refugiados-emigrantes-perguntas- frequentes/>. Acesso em: mar. 2018.

ANTUNES, Ricardo; PRAUN, Luci. A sociedade dos adoecimentos no trabalho. Serviço Social \& Sociedade, São Paulo, N. 123, p. 407-427, jul.-set. 2015.

ARAGONÉS, Ana María (Org.) Mercados de trabajos y migración internacional. México: UNAM, Instituto de Investigaciones Económicas, 2011.

BRASIL. Constituição da República Federativa do Brasil. Brasília: Senado Federal, 1988. 292p. 
BRASIL. Lei n. 7.418, de 16 de dezembro de 1985. Institui o vale-transporte e dá outras providências. Diário Oficial da União, Brasília/DF, 17 dez. 1985.

BRASIL. Câmara dos Deputados. Lei n. 605, de 5 de janeiro de 1949. Rio de Janeiro: Câmara dos Deputados, 1949.

BRASIL. Ministério da Educação. Revalidação de diplomas. 2017. Disponível em: <http://portal.mec.gov.br/revalidacao-de-diplomas>. Acesso em: 10 mar. 2018.

BRITO, Débora et al. Direitos humanos: diferentes cenários, novas perspectivas. Rio de Janeiro: Editor do Brasil, 2009.

CAVALCANTI, Leonardo. A inserção dos imigrantes no mercado de trabalho brasileiro. Relatório Anual 2017. Brasília: OBMigra, 2017.

DAL MAGRO, Marcia Luiza Pit; RISSON, Ana Paula. Reflexões acerca da chegada de imigrantes haitianos no Oeste de Santa Catarina e sua inserção no mercado de trabalho da região. Brasília: Laboratório de Estudos sobre as Migrações Internacionais, 2015.

ENGELS, Friedrich. Papel do trabalho na transformação do macaco em homem. São Paulo: Global, 1986.

FERNANDES, Duval; CASTRO, Maria da Consolação Gomes de. Projeto “Estudos sobre a Migração Haitiana ao Brasil e Diálogo Bilateral”. Brasília: MTE, 2014.

GIACOMINI, Taíze; BERNARTT, Maria de Lourdes. Educação para haitianos em contextos escolares e não escolares: realidade e desafios no sudoeste do Paraná. Projeto de Mestrado (Mestrado em Desenvolvimento Regional) - PósGraduação em Desenvolvimento Regional, Universidade Tecnológica Federal do Paraná, Pato Branco, 2015. 
IBGE - Instituto Brasileiro de Geografia e Estatística. Contagem Populacional. Rio de Janeiro: IBGE, 2017.

MAGALHÃES, Luís Aires. A imigração haitiana em Santa Catarina: perfil sociodemográfico do fluxo, contradições da inserção laboral e dependência das remessas no Haiti. 2017. Tese (Doutorado em Demografia) - Pós-Graduação em Demografia, Universidade Estadual de Campinas, Campinas, 2017.

MENDONÇA, Laís Maranhão Santos. Imigração e trabalho: luta por reconhecimento dos imigrantes no Brasil. 2014. Dissertação (Mestrado em Direito) - Pós-Graduação em Direito, Universidade de Brasília, Brasília, 2014.

MILESI, Rosita. Haitianos no Brasil: dados estatísticos, informações e uma recomendação. Brasília: Instituto Migrações e Direitos Humanos, 2016.

MIRAGLIA, Lívia Mendes Moreira. Trabalho escravo contemporâneo: conceituação à luz do princípio da dignidade da pessoa humana. 2008. Dissertação (Mestrado em Direito) - Pós-Graduação em Direito, Pontifícia Universidade Católica de Minas Gerais, Belo Horizonte, 2008.

OIT. Manual de capacitação e informação sobre gênero, raça, pobreza e emprego: guia para o leitor. Brasília: Organização Internacional do Trabalho, 2005.

ONU. Declaração Universal dos Direitos Humanos. Genebra: Organização das Nações Unidas/Assembleia Geral das Nações Unidas, Paris, 10 dez. 1948.

PASTORE, José. As mudanças no mundo do trabalho: leituras de sociologia do trabalho. São Paulo: LTr, 2006.

RAYMUNDO, Louise Rocha. A construção da política pública estadual de promoção e defesa dos direitos de migrantes e refugiados no estado do Paraná 2012-2015. Caderno IPARDES, Curitiba, v. 5, n. 1, p. 17-36, jan./jun. 2015. 
TEDESCO, João Carlos. Estrangeiros, extracomunitários e transnacionais: paradoxos da alteridade nas migrações internacionais: brasileiros na Itália. Passo Fundo: Editora UPF; Porto Alegre: Edipucrs; Chapecó: Argos, 2010.

VENDRUSCOLO, Adriele Eveline Dias et al. Crescimento e desenvolvimento profissional na indústria patobranquense: o caso da inserção de trabalhadores haitianos. In: CONGRESSO NACIONAL DE PESQUISA EM CIENNCIAS SOCIAIS APLICADAS, 5, 2016, Francisco Beltrão. Anais... Francisco Beltrão: CONAPE, 2016.

Endereço para correspondência:

Cristiane Tonezerer-tonezer@unochapeco.edu.br Servidão Anjo da Guarda, 295-D - Bairro Efapi 89809-900 Chapecó/SC, Brasil

Ademir Boeno-ade_boeno@yahoo.com.br Avenida Água Verde, 2140 - Vila Izabel 80240-070 Curitiba/PR, Brasil

MyriamAldana-aldana@unochapeco.edu.br Servidão Anjo da Guarda, 295-D - Bairro Efapi 89809-900 Chapecó/SC, Brasil 